\title{
A Simple Technique for Sustaining Solar Energy Production in Active Convective Coastal Regions
}

\author{
Moses E. Emetere, Marvel L. Akinyemi, and Etimbuk B. Edeghe \\ Department of Physics, Covenant University, Canaanland, PMB 1023, Ota, Nigeria \\ Correspondence should be addressed to Moses E. Emetere; emetere@yahoo.com
}

Received 19 March 2016; Accepted 17 July 2016

Academic Editor: Vishal Mehta

Copyright ( $) 2016$ Moses E. Emetere et al. This is an open access article distributed under the Creative Commons Attribution License, which permits unrestricted use, distribution, and reproduction in any medium, provided the original work is properly cited.

The climatic factors in the coastal areas are cogent in planning a stable and functional solar farm. 3D simulations relating the surface temperature, sunshine hour, and solar irradiance were adopted to see the effect of minute changes of other meteorological parameters on solar irradiance. This enabled the day-to-day solar radiation monitoring with the primary objective to examine the best technique for maximum power generation via solar option in coastal locations. The month of January had the highest turbulent features, showing the influence of weather and the poorest solar radiance due to low sunshine hour. Twenty-year weather parameters in the research area were simulated to express the systematic influence of weather of PV performance. A theoretical solar farm was illustrated to generate stable power supply with emphasis on the longevity of the PV module proposed by introducing an electronic concentrator pillar (CP). The pictorial and operational model of the solar farm was adequately explained.

\section{Introduction}

The quest to meet the energy budget of a growing economy [1] is of utmost importance. The energy option from fossil and nuclear sources has been reported severally to be dangerous because of the massive release of anthropogenic pollution [24] from automobiles, multipurpose generators, and industrial machinery. Extensively, anthropogenic gas emissions into the atmosphere may initiate climate change $[5,6]$, global warming, and so forth. Hence, the promotion of clean renewable energy source is the only way of curbing air pollution in the environment. Solar energy is described as the cleanest renewable energy whose source is the sun. The sun and its numerous events (known as solar activity) have been reported to be the main driver of climate change [7]. The solar activity in the tropical regions is quite high (compared to the polar region) to drive the global energy and convective processes. In the tropics, high solar activity is advantageous in operating a successful solar farm. The annual global radiation in tropical and subtropical regions is about 1600 $2200 \mathrm{kWh} / \mathrm{m}^{2}$. Solar farms in the tropic have capacities of generating electric power, ranging from 10 (Megawatts) MW to $150 \mathrm{MW}$ [8]. In the coastal area of the tropics, an increased solar activity culminates into an increased convective updraft and downdraft, cloud formation, frequent cloud movement [9], and so forth. These events in the coastal areas engender a process known as atmospheric shading. Atmospheric shading occurs when the cloud movement cast its shadow on the earth surface. Atmospheric shade is inimical to solar power generation because the solar cell is designed in such a way that little shade on one panel can gradually shut down solar power production. The bypass diodes assist in minimizing the effects of partial shading by preventing damage from reverse bias on partially shaded cell or cells. Bypass diodes allow the flow of electricity from nonshaded parts to pass by the shaded part of the module. However, the failure of the bypass diode has been reported [10]. It causes great power loss during large shading, hence, causing the module's performance to drop by $1 / 3$ instantly. The failure of the bypass diode is evident when probed by Signal Transmitter Device.

A major advantage of the coastal areas is the high precipitation level which helps to clean the surface of the solar panel for effective photoemission. Solar energy operators in the coastal areas are faced with challenges ranging from climate change, inefficient solar panel, durability of the solar panel, poor energy budget, and so forth. The estimated solar power 
reaching the earth is little above $1000 \mathrm{~W} / \mathrm{m}^{2}$ [13]. In Nigeria, about $1,770 \mathrm{TW} \mathrm{h} /$ year of solar energy falls on the entire land area of Nigeria [14]. By this estimation, if $10 \%$ of the solar energy can be harvested, the energy generation would be about 200 times more than the total energy obtained from fossil and hydroelectricity. This means that if solar energy is judiciously harvested, solar option is capable of meeting the energy needs of the whole world. An efficient harvest of the solar radiation within the tropics and specifically coastal areas depends on the efficiency of the solar panel used. The improvement of the PV farm is of utmost interest in the quest of maximizing the utilization of solar energy. The PV metamorphosis includes dye-sensitized solar cells with $11 \%$ efficiency, organic photovoltaic known as plastic solar cells with $8 \%$ efficiency, and III-V multijunction solar cells with over $40 \%$ efficiency. The PV technologies mentioned above do not yet contribute to the PV market, hence, the emergence of the concentrating solar power (CSP) technology. The CSP technology is presently enhanced by the smart grid concept to eliminate uncertainty and intermittency of solar generation.

Solar panels are made up of solar cells, that is, an array of photovoltaic (PV) cells. The primary requirement for a material to be used for solar cell application is its band gap. The band gap of the solar material is expected to be between $1.1 \mathrm{eV}$ and $1.7 \mathrm{eV}$ [15]. Solar cells are classified based on its inherent band gap. Types of solar cell include silicon solar cells, III-V group solar cells, and thin film solar cells. PV modules do not only convert solar irradiation directly into electric but also produce plenty of waste heat, which can be recovered for thermal use [16]. Materials used to fabricate the PV panels are monocrystalline silicon, polycrystalline silicon, microcrystalline silicon, copper indium selenide, and cadmium telluride [17]. The technology behind solar panels varies with respect to the manufacturer. Recently, the production of solar cell from silicon semiconductor is one of the latest inventions of the PV technologies. The concentrating solar power (CSP) technology is another recent technique for improving the functionality of the PV module. A typical CSP plant consists of three main subsystems: solar collector field, solar receiver, and a power conversion system [18]. The CSP option includes the collector and the receiver, parabolic trough, solar tower or central receiver, linear Fresnel, and dish Stirling [19]. The efficiency of the CSP is high in the tropical region. However, the efficiency of the CSP is greatly reduced in coastal region which is characterized by high convective activity and solar shading. Already advanced control techniques have been applied to concentrating solar power systems to overcome the problems caused by the sporadic nature of solar radiation [20]. Another way scientists sought to solve the irregular solar radiation problem is the use of storage systems [21]. Researchers have suggested the incorporation of the thermal energy storage (TES) system to the solar farm. This idea enables an efficient utilization of fluctuating solar energy on a continuous basis [22-24]. Recent research [25] has shown that the success of the TES depends on the type of fluid used to convey heat from the solar collector to the TEM. Gnaneswar Gude et al. [26] have shown that low temperature desalination systems are very efficient for TES.
This paper seeks to solve the challenges of solar radiation irregularities due to solar shading in the coastal region. It examines a comparative functional analysis of two types of PV solar panel randomly chosen. The PV solar panel was tested in a changing solar radiation noticed in the south west region of Nigeria. A model was propounded to mathematically represent the challenges of solar energy operators in coastal areas. Solution was proffered via adopting of electronic concentrator pillars in a prototype solar farm.

\section{Location of Study Area}

The study area is located on a narrow coastal plain of the Bight of Benin, specifically on the south west of Nigeria. It lies approximately on longitude $2.48^{\prime} \mathrm{E}$ and $3.26^{\prime} \mathrm{E}$, respectively, and latitude $6.24^{\prime} \mathrm{N}$ and $6.25^{\prime} \mathrm{N}$ (as shown in Figures 1 and 2). The detail of the location is expressed by Emetere and Akinyemi [27]. Coastal regions are influenced by geomorphological and oceanographical factors, for example, storm event and open-ocean convection intensity that controls the seasonal variability of the hydrology, hydrodynamics, and biogeochemistry [28].

\section{Methodology}

The theories used in the methodology have been propounded by Emetere and Akinyemi [27]. The dataset used for this study was obtained from Giovanni, Nigerian Meteorological Agency, and Davis weather station. The field work comprises primarily two PV modules from different producers, that is, SolarWorld and Sharp Solar as established in [27].

The voltage form is measured directly from the PV module, that is, using a multimeter set to direct current DC voltage. A manual data logger was used to obtain readings. The readings were collected every ten minutes every day between the hours of twelve noon and three in the afternoon $(3 \mathrm{pm})$ when the sun is believed to be at its peak.

The experiment was performed in the active days of December, 2013. The choice of December was as a result of the following:

(i) One-year data collected by the Davis weather station shows an average solar radiance in the months (Figure 3).

(ii) The peak days of December were captured using the Davis weather station (Figure 4).

The meteorological effect (ME) on the performance of the PV module will be established in the succeeding section. The varying solar radiation shows the clear evidence of ME in coastal areas. We propose that the coastal regions are characterized by solar sectional shading (SSS). Solar sectional shading is an atmospheric event due to cloud movements and formation over area, leading to physical shades over a region during solar radiation [27]. The evidence of weather on solar farm was done using 3D simulation of sunshine hour, solar irradiance, and surface temperature. 




FIGURE 1: Location of study area in the enclave of Nigeria.



Figure 2: Location of study coastal area.

\section{Evidence of Weather Effect on Solar Farm Setup}

A twenty-year dataset (1993-2012) obtained from Nigerian Meteorological Agency for the research site was used to investigate the weather effect on solar farms in the coastal area. The weather parameters are sunshine hour, solar irradiance, and surface temperature. The $3 \mathrm{D}$ representation of the weather parameter was articulated via the "surfer 8" software (see Figures 5-7). The shape enabled the instability of the weather parameters within two decades. For example, the months of January, February, March, May, July, September, 


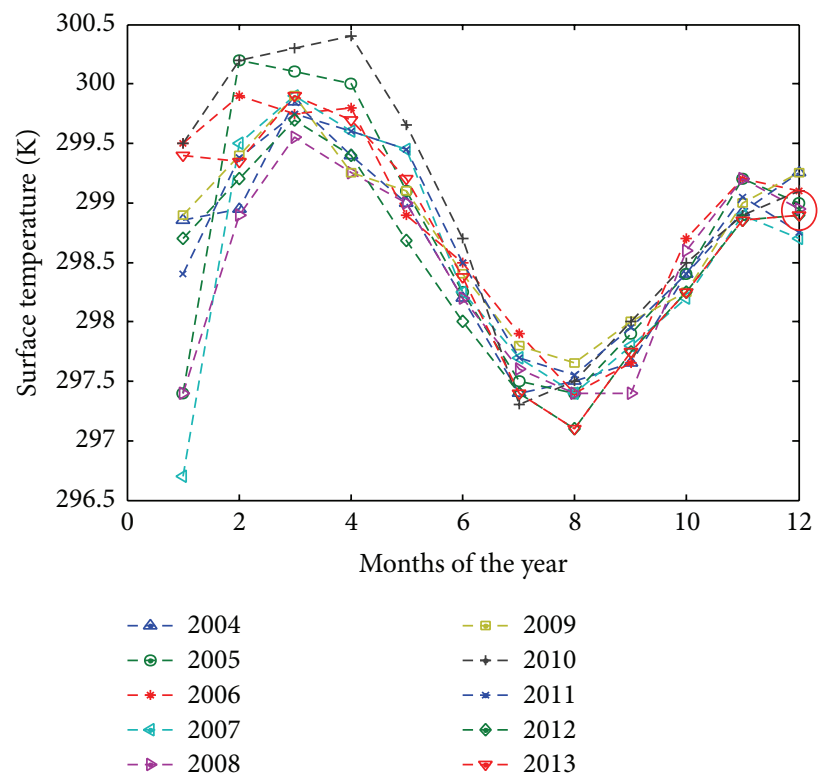

FIgURE 3: Monthly surface temperature data (2004-2013).



FIGURE 4: Ten-year surface temperature data (2004-2013).

October, November, and December showed massive instabilities over two decades while larger part of the months of April, June, and August showed stability.

\section{Field-Work Results}

The voltage-time graph of the four PV thin film module groups and temperature-time graph from the Davis weather station for active days of December are shown in Figure 9. The specific solar radiation trends were selected and discussed [27]. The undulating surface temperature which is a direct influence of solar radiation $[29,30]$ is captured in the voltage output. All groups responded to the first surface trough above $30^{\circ} \mathrm{C}$ (see the red arrow in Figures 8 and 9). The arrows show that there was a small voltage difference between the clean and dusty sharp PV modules. Also it is important to note that the coincidental intercepts between the clean and dusty PV modules are due to a basic principle; that is, the open-circuit voltage $V_{\mathrm{oc}}$ is inversely proportional to the temperature; that is, as the temperature increases, the voltage decreases. All the solar panels in each group responded differently to subsequent drop of solar radiation. Sometimes, CSW and DSW recover their sinusoidal form, that is, in accordance with the prevailing solar radiation.

A comparative study between Figures 8 and 9 shows a fluctuation between 140 and 180 minutes. Also, it can be interpreted that the fluctuation was as a result of temperature drop due to solar shading. Another kind of solar irradiance trend on the efficiency of the PV module is the affirmation of the two kinds of temperature rise, that is, an undulating temperature rise and a fair temperature rise. An undulating temperature rise is characterized by slant crest and trough. A fair temperature rise is neither linear nor parabolic. It is characterized by uniform or constant regions within its rise. Both groups of SolarWorld PV modules seem to perform better in a fair temperature rise. The sharp PV thin film module 

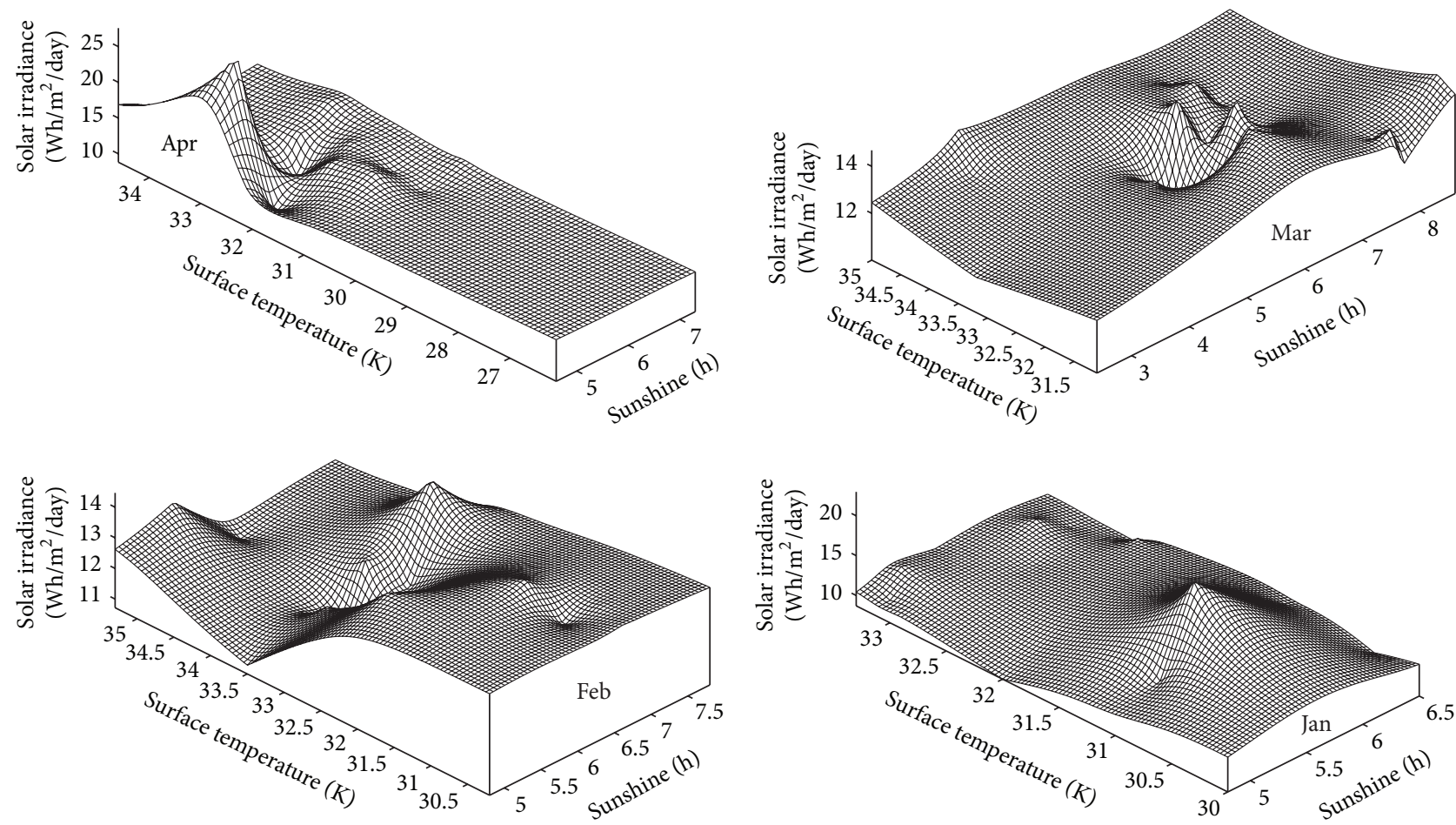

Figure 5: Weather parameter trend for January-April.
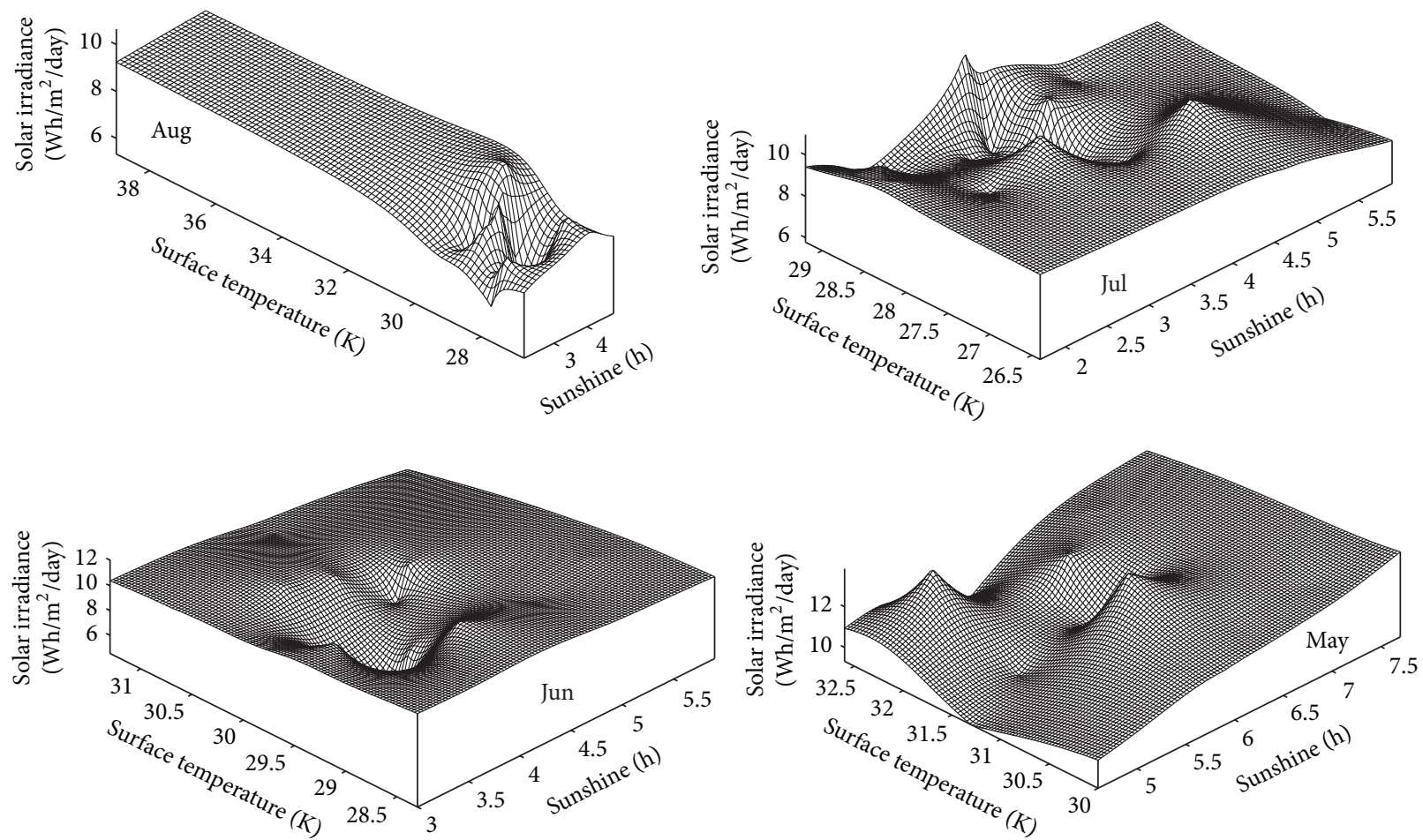

FIGURE 6: Weather parameter trend for May-August. 

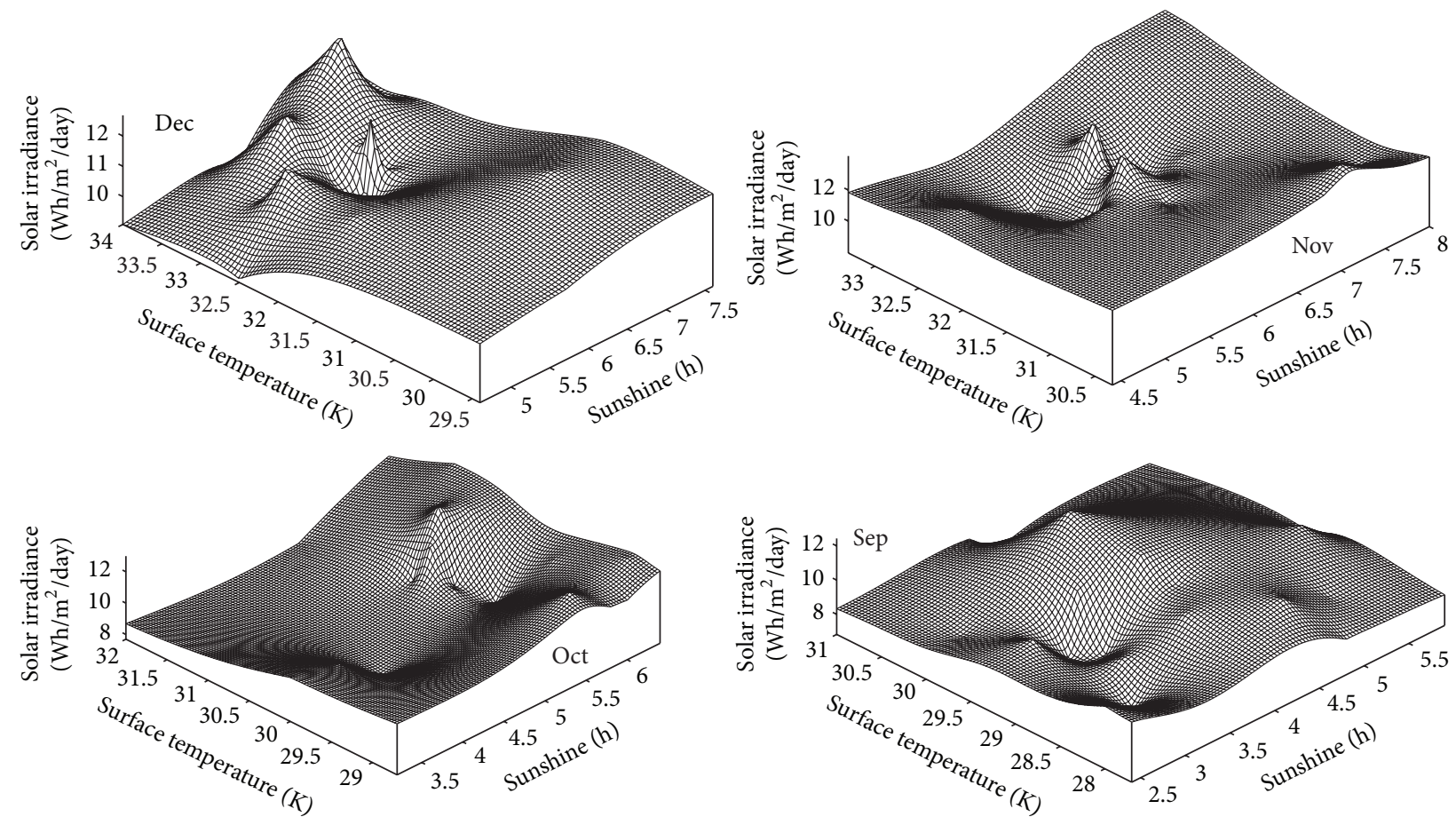

FiguRE 7: Weather parameter trend for September-December.

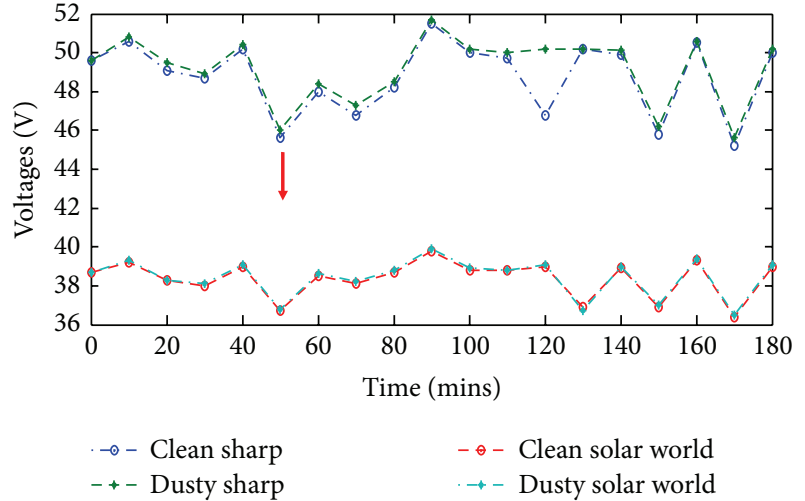

FIgURE 8: Voltage-time on day four (12:00-15:00 daily).

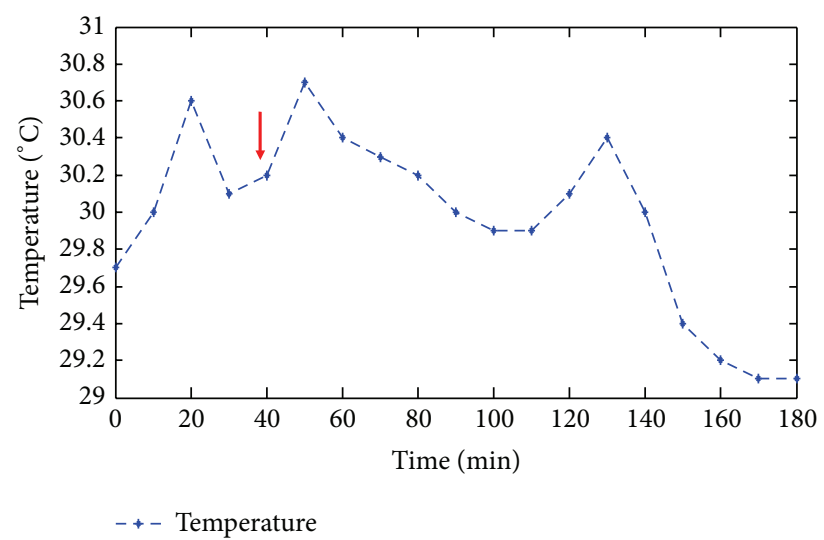

Figure 9: Temperature-time on day four (12:00-15:00 daily).



FIGURE 10: Voltage-time on day six (12:00-15:00 daily).

does not easily recover from sudden drop in temperature. SolarWorld PV module is more stable at this point. Also, the solar radiation may mimic a Gaussian distribution (see Figure 11). Its output as seen in Figure 10 supports a fairly stabilized voltage output.

\section{The Theoretical Solar Farm Suggested for Coastal Areas}

PV panels mounted in coastal region (as illustrated in the previous sections) can sometimes be inefficient in harvesting all available energy from sunlight because of the SSS, shape of PV module, and varying solar intensity throughout the day. Therefore, the results shown in previous sections are very 


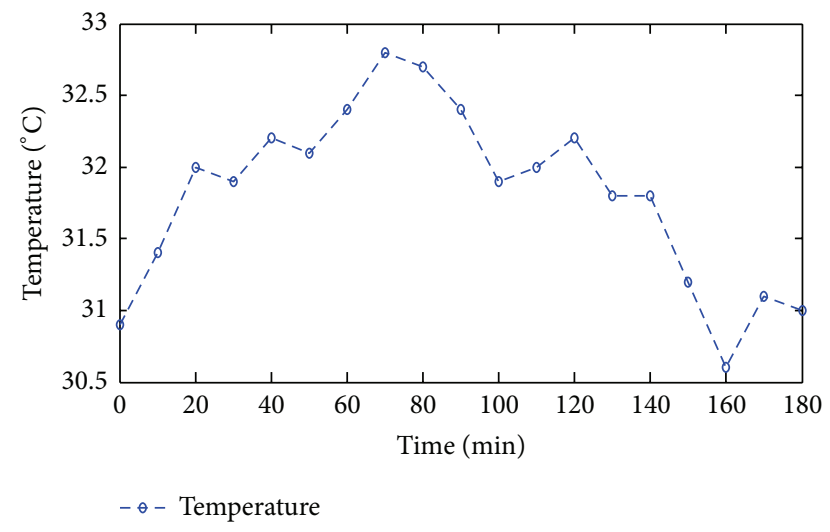

Figure 11: Temperature-time on day six (12:00-15:00 daily).



FIGURE 12: Solar farm with concentrator pillars at SSS boundaries.

important in planning a solar farm for coastal region. We maintain the basic parameters for setting up a solar farm. The only improvement proposed for the solar farm setup is the inclusion of the electronic concentrator pillars (CP) which are expected to provide uniform solar radiation for the PV modules. Solar concentrators are efficient in tropic region except for its coast plain. The size of the SSS may be large over an area. This is due to formation of cloud forms. When the size of the SSS is large, the solar tracker (which mounts the concentrator) may be inefficient in a solar farm. The technique suggested in this research is hinged on two assumptions; that is, the solar farm must occupy a fairly large area for the electronics concentrator to keep track of the position of the sun; the mirrors and transmitting lens should be mounted on different solar tracker. On a smaller solar farm, the success of this technique lies in the expertise of personnel to determine of the SSS boundaries so as to locate the concentrator pillars (CP) as shown in Figure 12. The CP is made up of majorly transmitting lens, mirrors, solar radiation relays, and switching integrated circuit. All the electronic $\mathrm{CP}$ are configured to operate at almost equal voltage output. When there is SSS in some part, there is a drastic drop in the voltage supply of the particular CP, that is, within the circuitry of the CP. This action initiates the transmitting lens of the CP in the active solar region to switch on and transmits radiation to other neighboring $\mathrm{CP}$. We propose that this technique could maintain an almost uniform solar radiation (see Figure 12) during the active hours of the day.

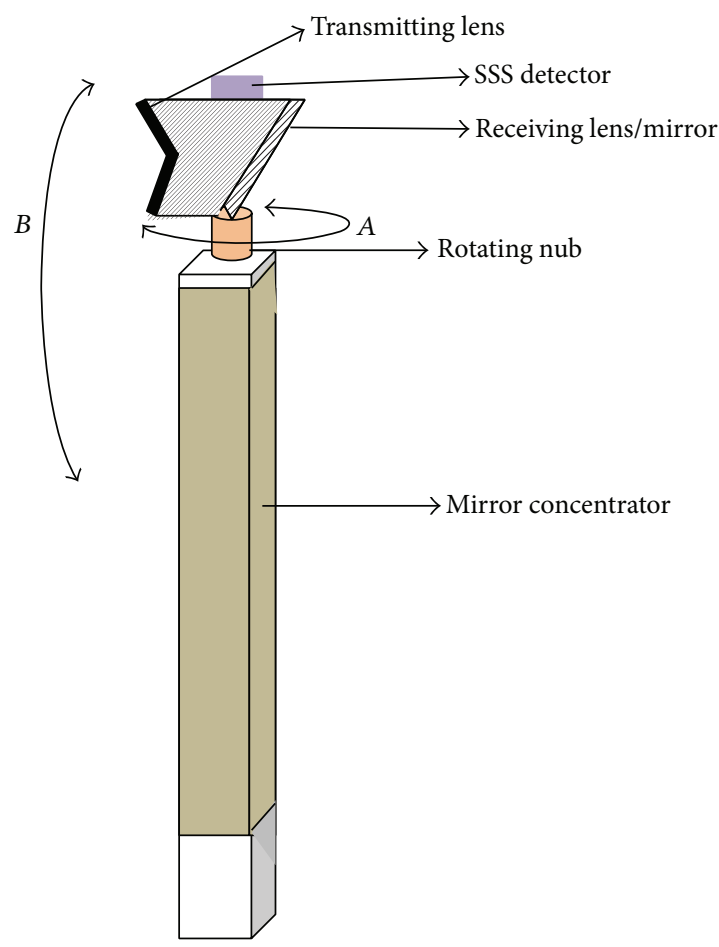

FIGURE 13: Pictorial model of a concentrator pillar.

We gave a pictorial model for the electronic CP (Figure 13). The electronics diagram was not reported to allow for ingenuity by researchers or manufacturers.

The electronic concentrator pillar is made up of a mirror wall for reflectivity rebound. An improved mirror may be used, that is, mirror symmetrical dielectric totally internally reflecting concentrator (MSDTIRC). Davis [31] and Muhammad-Sukki et al. [30] recently highlighted the advantages of the MSDTIRC, that is, increasing the electrical output of a solar photovoltaic (PV) system and reducing the amount of the PV cell material needed, hence minimizing the production cost of the system. The rotating nub enables both zenith and azimuth rotation to locate the nearest transmitting CP (see " $A$ " in Figure 13). The casing of the transmitting lens is designed to provide a continuous radiating guide. This process is almost synonymous to the fundamental principles of a wave guide or resonating cavity. The transmitting lens has a vertical/zenith rotation (see " $B$ " in Figure 13) whose stability depends on the solar sensors of neighboring CP. The solar sensor on the transmitting $\mathrm{CP}$ works on the principle of back-scattering. This process enables it to detect the radiational magnitude of the nearest receiving CP. The transmitting CP trips off as soon as solar detector receives a backscattered solar radiation that is equal or nearly equal to SSS detector. This process repeats itself if any SSS detector switches off. The sensors of the electronic CP are programmed to operate at similar magnitude. If the radiational magnitude of any CP falls below others, the rotating nub of the nearest receiving and transmitting $\mathrm{CP}$ rotates to detect each of them. 


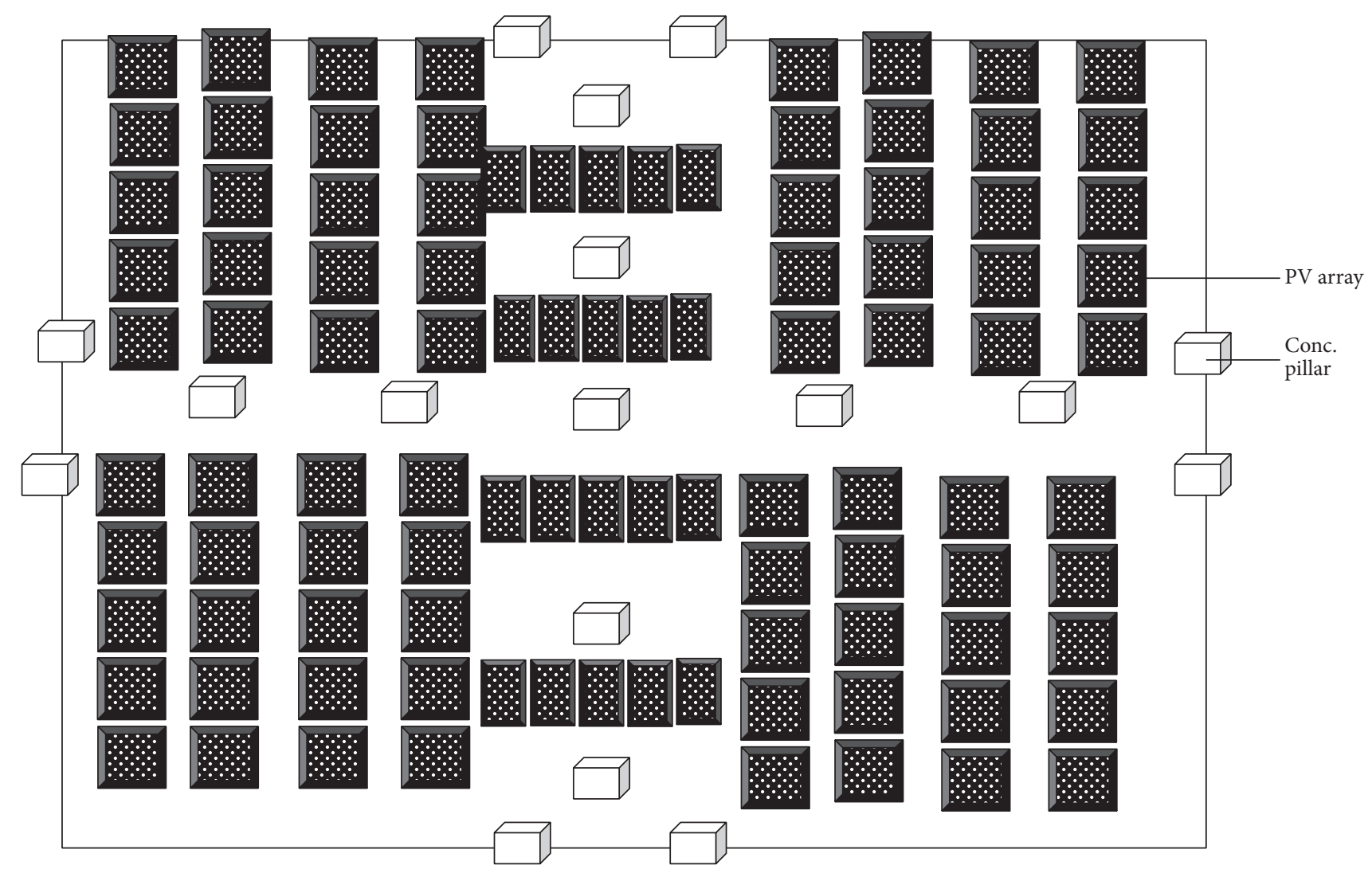

FIgURE 14: Aerial view of the solar farm.

Further calculations are required for maximum application of this technique. The aerial view of the solar farm is shown in Figure 14.

The concentrator pillars at the boundaries are used to correct the shades created by the concentrator pillar within the solar farm. The economic viability of this project is dependent on the quality of the material used. Hence, the cost may vary due to availability of material or components used to build the concentrator pillars.

The validity of the $\mathrm{CP}$ technology to improve the PV module efficiency is evident in its transmittance and energy yield. The transmittance may be surface reflection $\left(T_{\mathrm{sr}}\right)$ or geometry loss $\left(T_{\mathrm{gl}}\right)$. This can be expressed mathematically:

$$
T_{\mathrm{sr}}=\left(\frac{n_{t} \cos \theta_{t}}{2 n_{i} \cos \theta_{i}}\right)\left(t_{\perp}^{2}+t_{\|}^{2}\right) .
$$

Here $n_{i}$ is the index of refraction for the ray in the incident media, $n_{t}$ is the index of refraction for the ray in the transmitted media, and $\theta_{i}$ and $\theta_{t}$ are incident and refracted angles. Consider

$$
T_{\mathrm{gl}}=1-\left(\frac{s-b}{d}\right)
$$

Here $s$ is the radius loss distance, $b$ is the projected draft, and $d$ is the transmission distance. Since geometry loss arises from the draft surface and prism tip rounding of the lens facets,

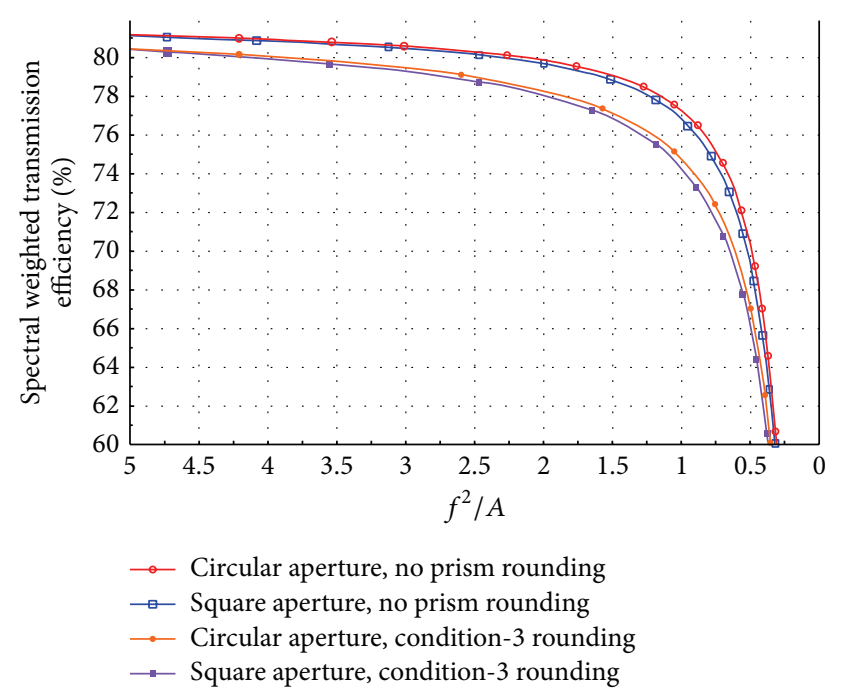

Figure 15: Circular versus square lens aperture transmittance comparison when plotted on an axis of squared focal ratio $f^{2} / A$. Reference [11].

the prospect of the lens array design in Figure 11 to improve the efficiency of the PV had been expressed in Figure 15.

The spectra weighted transmission efficiency for square lens aperture is lower than circular lens. This means that when rays are transmitted from the $\mathrm{CP}$ onto the $\mathrm{PV}$ module, the tendency of geometry loss is lower than the circular lens. 


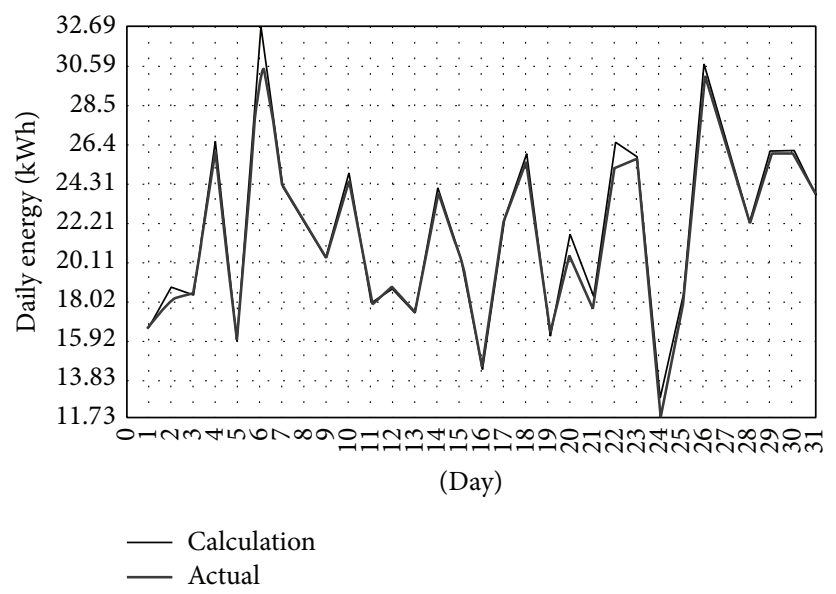

FIGURE 16: Daily energy output from polycrystalline PV module. Reference [12].

The validity of the energy yield prediction of a PV model has been expressed in [12] shown in Figure 16.

The energy yield of the PV module is given as [32]

$$
E=a_{1} H+a_{2} H T_{\max }^{-2}+a_{3} T_{\max } .
$$

Here $H$ is the direct normal irradiation, $T$ is the temperature, and $a_{1}, a_{2}$, and $a_{3}$ are regression coefficients. The three terms on the right hand side give linear trend lines, that is, the first two for each installation (CP and PV module) and the third for both installations. Hence, CP installation can be modeled linearly and rarely generate energy at very low levels of irradiation [10]; hence, the performance ratio (PR) is expressed as

$$
\mathrm{PR}=\frac{0.85 E}{H}
$$

We propose that " $n$ " is number of hours per day; then

$$
\mathrm{PR}=\frac{0.85 E}{H} n \text {. }
$$

Since performance ratio is the ratio of production energy to expected energy and the regression coefficient is negligible due to the CP, then the expected energy yield can be written as

$$
E_{e}=\frac{T_{\text {max }}}{\mathrm{PR}-\left(0.85 n+0.85 n T_{\max }^{-2}\right)} .
$$

The second term of the denominator was discarded because it is not dependent on temperature. This term becomes the source of error when the system is at its minimum energy generation at very low levels of irradiation; hence,

$$
E_{e}=\frac{T_{\max }}{\mathrm{PR}-0.85 n T_{\max }^{-2}} .
$$

Equation (5) was analyzed at various performance ratios, that is, $0.5,0.85$, and 1.5 (Figure 17).
From the above simulation, the minimum energy expectation is $65 \mathrm{KWh}$ at a performance ratio, that is, unity. The expected energy yield rises as the duration of the CP installation increases. From Figure 17, the linearity of the CP installation was affirmed. Hence if we intend to generate twice the production energy $(\mathrm{PR}=0.5)$, the maximum expected energy yield would be $135 \mathrm{KWh}$.

\section{Conclusion}

It was analytically and numerically proven that climatic factors influence solar radiation in coastal regions. This means that solar PV efficiency would be greatly affected. The day-to-day solar radiation pattern experiment was performed in the tropical coastal areas. The solar radiation pattern is characterized by undulating rise, fair rise, and Gaussian distribution. The danger of the irregular solar radiation features can be seen to mitigate individual performance of the solar cells and its lifecycle. The reason for irregular solar radiation was adduced to solar sectional shading because it is prevalent in the coastal region and triggers the type of solar pattern for the day/month/year. The SSS is an atmospheric event which occurs due to cloud formation and movements over coastal area. A mathematical model was propounded to explain the collective solar radiation over a massive coastal area. The surface temperature or the solar intensity is inversely proportional to the area. The practical solution for enhancing solar PV efficiency in the coastal areas was suggested via the introduction of electronic concentrator pillars in a proposed solar farm. The pictorial and operational model was adequately explained.

\section{Competing Interests}

The authors declare no conflict of interests. 


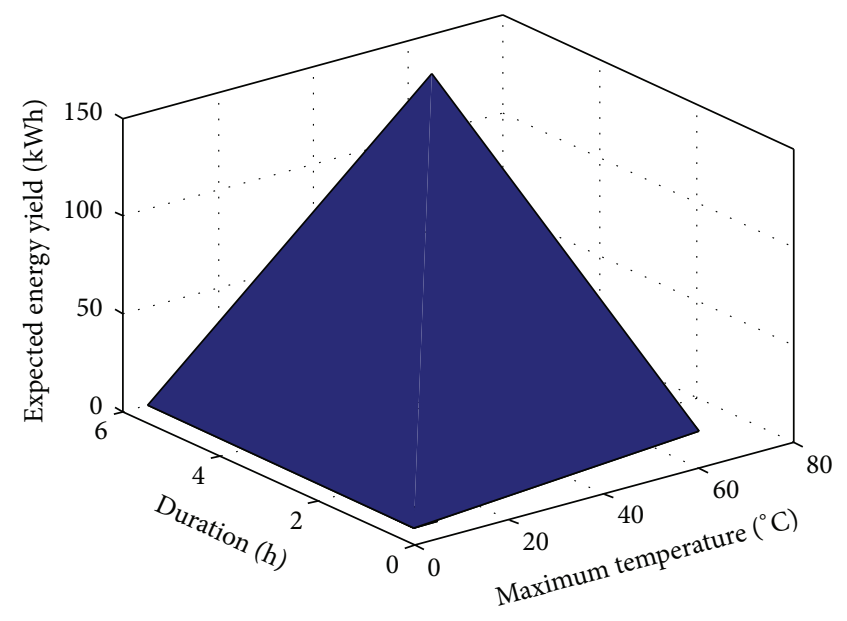

(a)

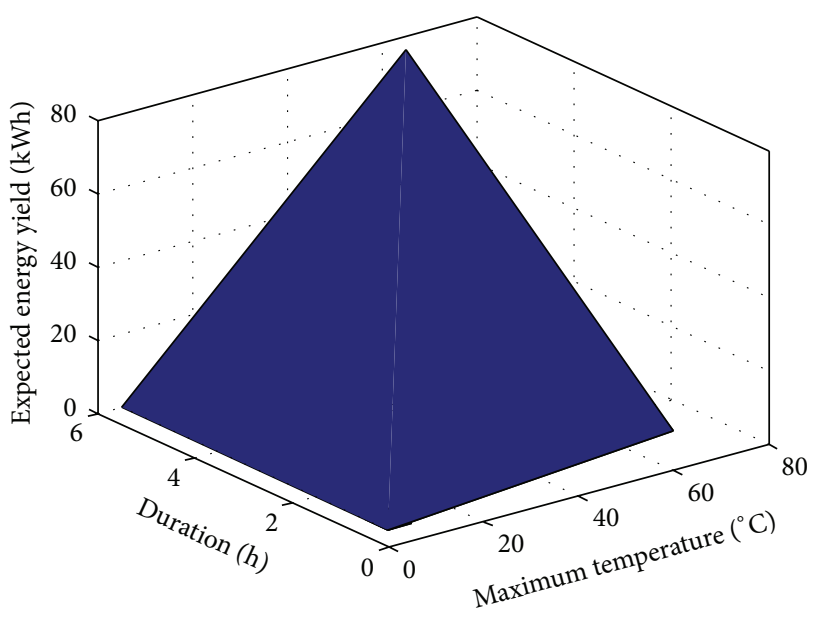

(b)

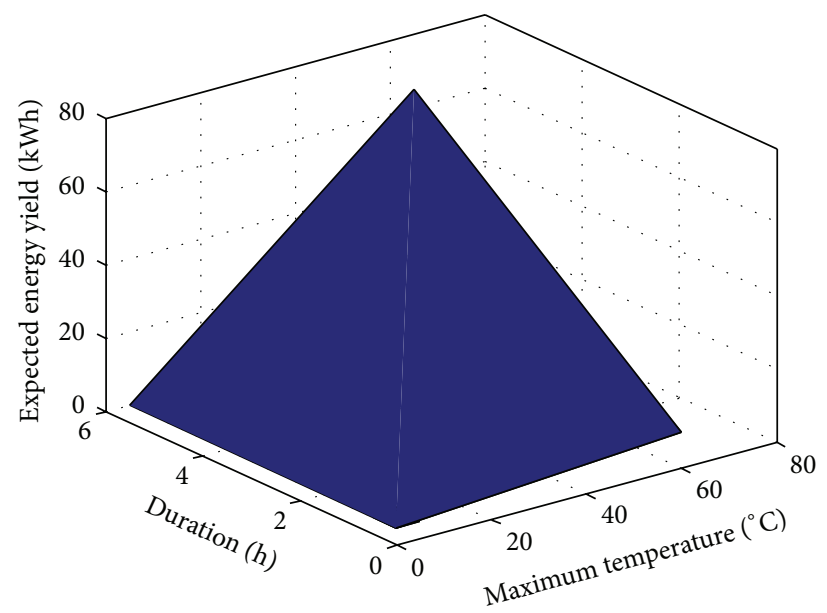

(c)

Figure 17: (a) Energy yield when $P R=0.5$. (b) Energy yield when $P R=0.85$. (c) Energy yield when $P R=1$.

\section{Acknowledgments}

The authors appreciate the host institution for their partial sponsorship. The authors appreciate the contributions of Jennifer Emetere.

\section{References}

[1] V. Devabhaktuni, M. Alam, S. Shekara Sreenadh Reddy Depuru, R. C. Green II, D. Nims, and C. Near, "Solar energy: trends and enabling technologies," Renewable and Sustainable Energy Reviews, vol. 19, pp. 555-564, 2013.

[2] M. E. Emetere and M. L. Akinyemi, "Modeling of generic air pollution dispersion analysis from cement factory," Analele Universitatii din Oradea-Seria Geografie, no. 1, Article ID 231123-628, pp. 181-189, 2013.

[3] M. E. Emetere, "Modeling of particulate radionuclide dispersion and deposition from a cement factory," Annals of Environmental Science, vol. 7, no. 6, pp. 71-77, 2013.

[4] A. Brown, "Aerosol choices matter," Nature Climate Change, vol. 2, pp. 75-79, 2012.
[5] A. Tsikalakis, T. Tomtsi, N. D. Hatziargyriou et al., "Review of best practices of solar electricity resources applications in selected Middle East and North Africa (MENA) countries," Renewable and Sustainable Energy Reviews, vol. 15, no. 6, pp. 2838-2849, 2011.

[6] S. Keleș and S. Bilgen, "Renewable energy sources in Turkey for climate change mitigation and energy sustainability," Renewable and Sustainable Energy Reviews, vol. 16, no. 7, pp. 5199-5206, 2012.

[7] K. G. McCracken, J. Beer, and F. Steinhilber, "Evidence for planetary forcing of the cosmic ray intensity and solar activity throughout the past 9400 years," Solar Physics, vol. 289, no. 8, pp. 3207-3229, 2014.

[8] M. Jacobson, "Review of solutions to global warming, air pollution, and energy security," Tech. Rep., Stanford University, Stanford, Calif, USA, 2008.

[9] M. E. Emetere, "Forecasting hydrological disaster using environmental thermographic modeling," Advances in Meteorology, vol. 2014, Article ID 783718, 9 pages, 2014.

[10] C. Greacen and D. Green, "The role of bypass diodes in the failure of solar battery charging stations in Thailand," Solar Energy Materials and Solar Cells, vol. 70, no. 2, pp. 141-149, 2001. 
[11] A. M. Omar, M. Z. Hussin, S. Shaaria, and K. Sopianb, "Energy yield calculation of the grid connected photovoltaic power system," in Computer Applications in Environmental Sciences and Renewable Energy, pp. 162-167, WSEAS Press, 2014.

[12] E. Skoplaki and J. A. Palyvos, "On the temperature dependence of photovoltaic module electrical performance: a review of efficiency/power correlations," Solar Energy, vol. 83, no. 5, pp. 614-624, 2009.

[13] E. Hoff and M. Cheney, "The idea of low cost photovoltaic," Energy Journal, vol. 93, article 17, 2000.

[14] S. Olayinka Oyedepo, "Energy and sustainable development in Nigeria: the way forward," Energy, Sustainability and Society, vol. 2, no. 1, article 15, pp. 1-17, 2012.

[15] V. V. Tyagi, S. C. Kaushik, and S. K. Tyagi, "Advancement in solar photovoltaic/thermal (PV/T) hybrid collector technology," Renewable and Sustainable Energy Reviews, vol. 16, no. 3, pp. 1383-1398, 2012.

[16] Y. Tian and C. Y. Zhao, "A review of solar collectors and thermal energy storage in solar thermal applications," Applied Energy, vol. 104, pp. 538-553, 2013.

[17] T. M. Razykov, C. S. Ferekides, D. Morel, E. Stefanakos, H. S. Ullal, and H. M. Upadhyaya, "Solar photovoltaic electricity: current status and future prospects," Solar Energy, vol. 85, no. 8, pp. 1580-1608, 2011.

[18] M. S. Jamel, A. Abd Rahman, and A. H. Shamsuddin, "Advances in the integration of solar thermal energy with conventional and non-conventional power plants," Renewable and Sustainable Energy Reviews, vol. 20, pp. 71-81, 2013.

[19] X. Py, Y. Azoumah, and R. Olives, "Concentrated solar power: current technologies, major innovative issues and applicability to West African countries," Renewable and Sustainable Energy Reviews, vol. 18, pp. 306-315, 2013.

[20] E. F. Camacho, F. R. Rubio, M. Berenguel, and L. Valenzuela, "A survey on control schemes for distributed solar collector fields. Part II: advanced control approaches," Solar Energy, vol. 81, no. 10, pp. 1252-1272, 2007.

[21] U. Desideri and P. E. Campana, "Analysis and comparison between a concentrating solar and a photovoltaic power plant," Applied Energy, vol. 113, pp. 422-433, 2014.

[22] J. J. Navarrete-Gonzaález, J. G. Cervantes-de Gortari, and E. Torres-Reyes, "Exergy analysis of a rock bed thermal storage system," International Journal of Exergy, vol. 5, no. 1, pp. 18-30, 2008.

[23] I. M. Michaelides, S. A. Kalogirou, I. Chrysis et al., "Comparison of performance and cost effectiveness of solar water heaters at different collector tracking modes in Cyprus and Greece," Energy Conversion and Management, vol. 40, no. 12, pp. 12871303, 1999.

[24] S. Karsli, "Performance analysis of new-design solar air collectors for drying applications," Renewable Energy, vol. 32, no. 10, pp. 1645-1660, 2007.

[25] F. Cavallaro, "Fuzzy TOPSIS approach for assessing thermalenergy storage in concentrated solar power (CSP) systems," Applied Energy, vol. 87, no. 2, pp. 496-503, 2010.

[26] V. Gnaneswar Gude, N. Nirmalakhandan, S. Deng, and A. Maganti, "Low temperature desalination using solar collectors augmented by thermal energy storage," Applied Energy, vol. 91, no. 1, pp. 466-474, 2012.

[27] M. E. Emetere and M. L. Akinyemi, "Weather effect on photovoltaic module adaptation in coastal areas," International Journal of Renewable Energy Research, vol. 5, no. 3, pp. 821-825, 2015.
[28] M. Stabholz, X. Durrieu de Madron, M. Canals et al., "Impact of open-ocean convection on particle fluxes and sediment dynamics in the deep margin of the Gulf of Lions," Biogeosciences, vol. 10, no. 2, pp. 1097-1116, 2013.

[29] H. van Loon, G. A. Meehl, and J. M. Arblaster, "A decadal solar effect in the tropics in July-August," Journal of Atmospheric and Solar-Terrestrial Physics, vol. 66, no. 18, pp. 1767-1778, 2004.

[30] F. Muhammad-Sukki, S. H. Abu-Bakar, R. Ramirez-Iniguez et al., "Mirror symmetrical dielectric totally internally reflecting concentrator for building integrated photovoltaic systems," Applied Energy, vol. 113, pp. 32-40, 2014.

[31] A. Davis, "Raytrace assisted analytical formulation of Fresnel lens transmission efficiency," in Novel Optical Systems Design and Optimization XII, vol. 7429 of Proceedings of SPIE, pp. D1D12, San Diego, Calif, USA, August 2009.

[32] F. J. Gómez-Gil, X. Wang, and A. Barnett, "Analysis and prediction of energy production in concentrating photovoltaic (CPV) installations," Energies, vol. 5, no. 3, pp. 770-789, 2012. 



Carbohydrate Chemistry



The Scientific World Journal
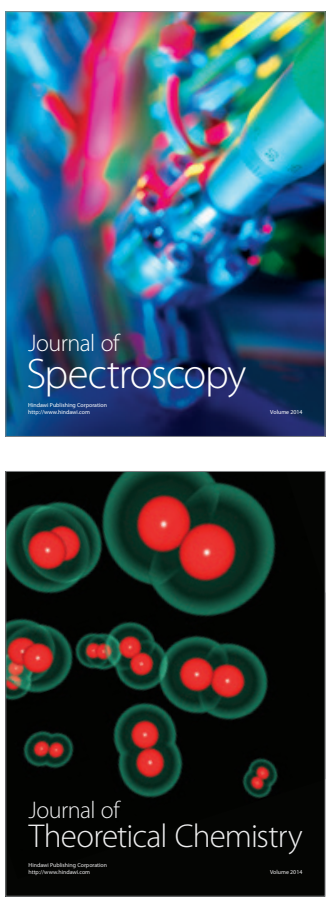
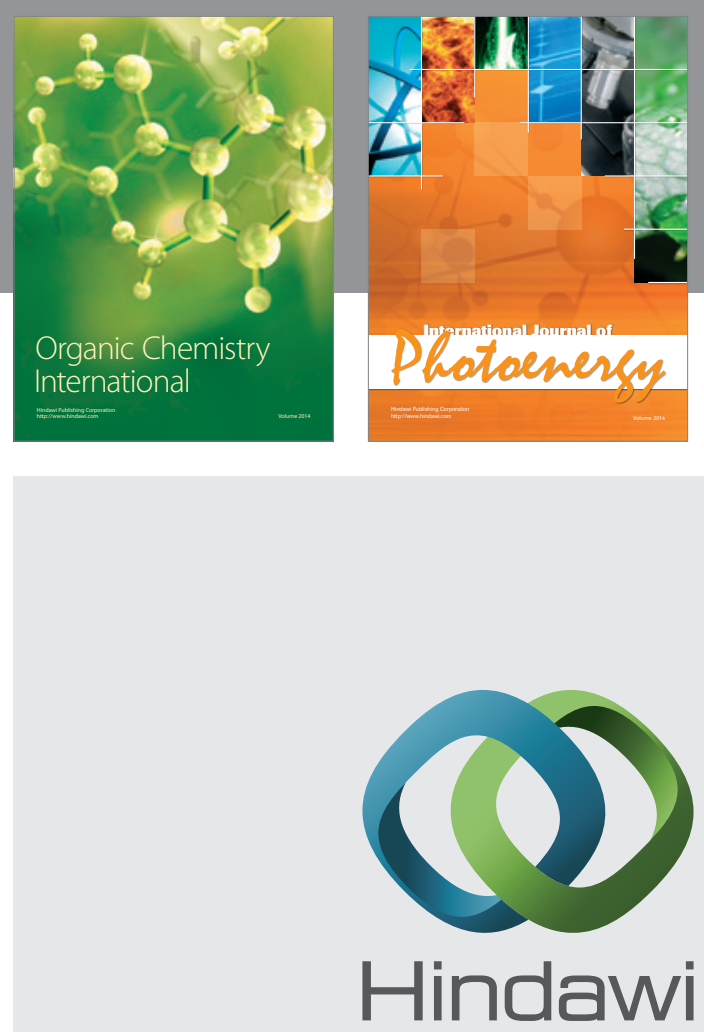

Submit your manuscripts at

http://www.hindawi.com

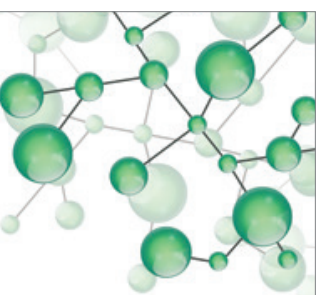

International Journal of

Inorganic Chemistry

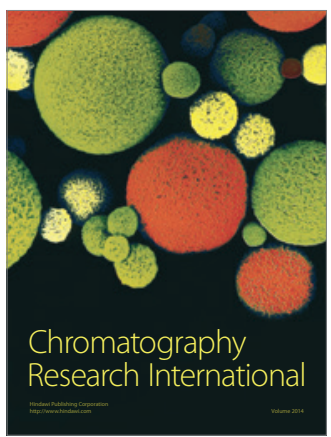

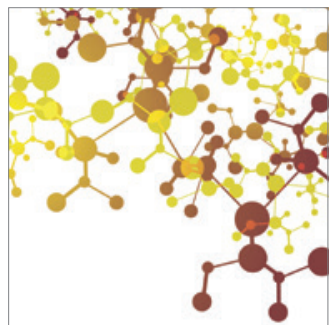

Applied Chemistry
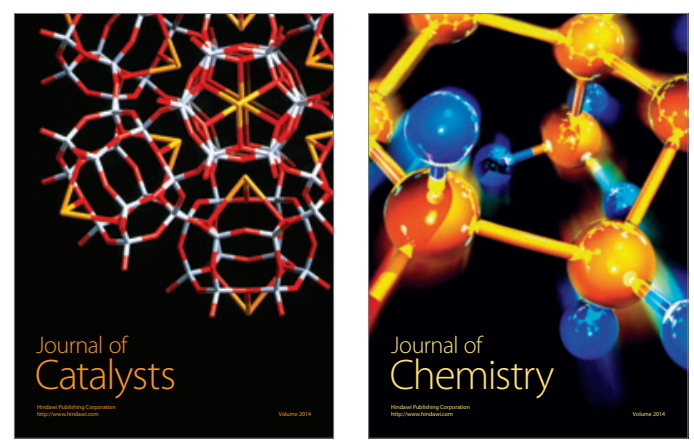
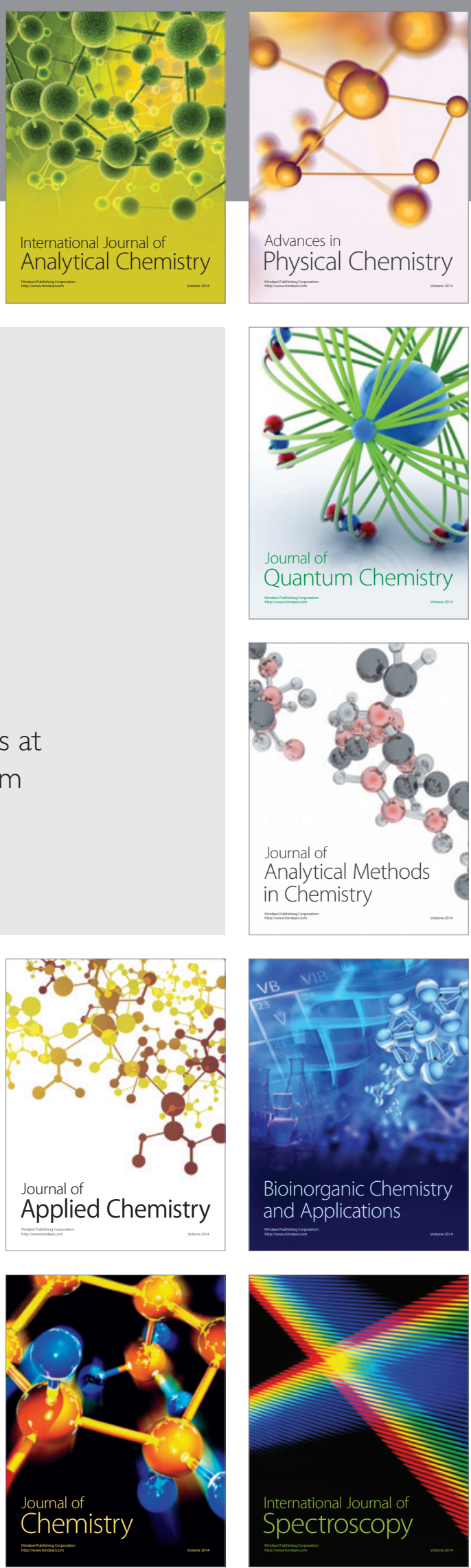